\title{
Thermodynamic Analysis of Suppressant-Enhanced Overpressure in the FAA Aerosol Can Simulator
}

\author{
GREGORY LINTERIS ${ }^{1}$, FUMIAKI TAKAHASHI ${ }^{2}$, VISWANATH KATTA ${ }^{3}$, HARSHA CHELLIAH ${ }^{4}$, \\ and OLIVER MEIER ${ }^{5}$ \\ ${ }^{1}$ National Institute of Standards and Technology \\ 100 Bureau Dr., Gaithersburg, MD 20899 USA \\ ${ }^{2}$ Case Western Reserve University \\ Cleveland, OH 44106 USA \\ ${ }^{3}$ Innovative Scientific Solutions, Inc. \\ Dayton, $\mathrm{OH} 45440$, USA \\ ${ }^{4}$ Mechanical and Aerospace Engineering \\ University of Virginia, Charlottesville, VA USA \\ ${ }^{5}$ The Boeing Company \\ Seattle, WA 98124 USA
}

\begin{abstract}
The fire suppressant $\mathrm{CF}_{3} \mathrm{Br}$ has been banned for most applications but it is still used in come critical applications for which suitable replacements have not yet been found. One such application is the suppression of cargo-bay fires in aircraft. Recently, the agents $\mathrm{C}_{2} \mathrm{HF}_{5}$ (pentafluoroethane, HFC-125), and bromotrifluoropropene $\left(\mathrm{C}_{3} \mathrm{H}_{2} \mathrm{~F}_{3} \mathrm{Br}\right.$, 2-BTP) have been evaluated in a mandated Federal Aviation Administration (FAA) test, in which a simulated explosion of an aerosol can must be suppressed by the agent. Unfortunately, unlike $\mathrm{CF}_{3} \mathrm{Br}$, either agent, when added at approximately one-half their inerting concentration, created a higher over-pressure in the test chamber than in tests with no agent present (thus failing the test). Similar combustion enhancement has been described in other experiments for certain conditions; however, explanation of the phenomena is lacking. As a first step in understanding this surprising result, the thermodynamics of the chemical systems are examined to predict the over pressure. For all of the cases examined, the over-pressure was predicted well by assuming that the fuel-agent-air ratio is that which produces the peak temperature, or peak $\mathrm{CO}_{2}$. The details of the three chemical systems are examined to provide insight into the anomalous behavior.
\end{abstract}

KEYWORDS: explosions, suppression, fire chemistry, Halon alternatives.

\section{INTRODUCTION}

The effective fire suppressant $\mathrm{CF}_{3} \mathrm{Br}$ (Bromotrifluoromethane, Halon 1301) has been banned from production by the Montreal Protocol due to its destruction of stratospheric ozone. While a critical-use exemption has been granted to the aviation industry for use of recycled Halon in cargo bay fire suppression, the European Union requires Halon replacement in new design aircraft by 2018 and in existing aircraft by 2040. Several replacements have been proposed, but they have all been found to produce enhanced burning in the FAA Simulated Aerosol Can test [1], and hence they fail FAA's Minimum Performance Standard [2]. In particular, $\mathrm{C}_{2} \mathrm{HF}_{5}$ (pentafluoroethane; HFC-125), and bromotrifluoropropene $\left(\mathrm{C}_{3} \mathrm{H}_{2} \mathrm{~F}_{3} \mathrm{Br}, 2-\mathrm{BTP}\right)$ produce higher peak pressures in a simulated cargo bay when they are added at concentrations less than that required to completely suppress a simulated aerosol can explosion.

The particular tests in which the unwanted enhanced pressure rise occurred were performed in the aerosol can explosion simulator at the FAA Technical Center by Reinhardt and co-workers [1,3]. The test consisted of a pressure vessel, $11400 \mathrm{~L}$, simulating an aircraft cargo bay container in which a fire causes the explosion of an over-heated aerosol can. In the simulator, a fast-acting valve releases a mixture of propane, ethanol, and water from a heated container $(16.2 \mathrm{bar} \pm 0.33 \mathrm{bar})$ into the chamber, which is filled with either air or air with added suppressant. Sparks from a DC arc, located $91.4 \mathrm{~cm}$ downstream of the valve opening, ignite the fuel from the aerosol can simulator, creating an expanding fire ball (if the overall mixture is explosive). The resulting heat release from reaction of the fuel and oxidizer raises the temperature, and hence the pressure, of the contents of the chamber. The fire-ball growth and ensuing pressure rise occur in an elapsed time of about $1 \mathrm{~s}$. During each test, pressure transducers, thermocouples, 
gas sampling probes, and a video camera record the pressure, temperature, agent and oxygen concentration, as well as visual images at select locations in the chamber.

The results of the FAA tests analyzed here are shown in Table 1. Without agent, the aerosol can contents ignited, creating a fireball which yielded a peak final temperature of around $180{ }^{\circ} \mathrm{C}$ and final rise of about 1.7 bar (25 psig) above ambient. With HFC-125 at volume fractions of $6.2 \%, 8.9 \%$, and $11.0 \%$, the peak pressure rise was about 3.6 bar (53 psig), whereas for $13.5 \% \mathrm{HFC}-125$, no pressure rise occurred. For 2BTP, volume fractions of $3 \%$ or $4 \%$ both gave a pressure rise of $4.3 \mathrm{bar}$ (63 psig), and volume fractions of $5 \%$ or $6 \%$ gave a pressure rise of about 6.7 bar (98 psig). The goal of the present work is to understand the reasons for the enhanced pressure rise which occurs with HFC-125 and 2-BTP addition, and the lack of this effect with added $\mathrm{CF}_{3} \mathrm{Br}$.

Table 1. Results of FAA Simulated Aerosol Can Test with no agent, 2-BTP, $\mathrm{CF}_{3} \mathrm{Br}$, and HFC-125.

\begin{tabular}{ccccccc}
$\begin{array}{c}\text { FAA } \\
\text { run no. }\end{array}$ & Agent & $\begin{array}{c}\Delta \boldsymbol{P}_{\text {initial }} \\
(\mathbf{b a r})\end{array}$ & $\begin{array}{c}\text { Agent volume } \\
\text { fraction }(\boldsymbol{\%})\end{array}$ & $\begin{array}{c}\boldsymbol{T}_{\text {initial }} \\
\left({ }^{\circ} \mathbf{C}\right)\end{array}$ & $\begin{array}{c}\boldsymbol{T}_{\text {final }} \\
\left({ }^{\circ} \mathbf{C}\right)\end{array}$ & $\begin{array}{c}\Delta \boldsymbol{P}_{\text {final }} \\
(\mathbf{b a r})\end{array}$ \\
\hline & & & & & & \\
3 & none & 0 & 0 & 18.3 & 197 & 1.75 \\
4 & none & 0 & 0 & 20.0 & 164 & 1.61 \\
5 & $2-B T P$ & 0 & 3 & 21.1 & 569 & 4.34 \\
6 & $2-B T P$ & 0 & 4 & 18.3 & 591 & 4.34 \\
9 & $2-B T P$ & 0 & 5 & 18.9 & 677 & 6.89 \\
13 & $2-B T P$ & 0 & 6 & 17.2 & 797 & 6.41 \\
16 & $\mathrm{CF}_{3} B r$ & 0 & 2.5 & 11.9 & 18.3 & 0.28 \\
17 & HFC-125 & 0 & 8.9 & & 664 & 3.65 \\
19 & HFC-125 & 0 & 11 & & 575 & 3.58 \\
23 & HFC-125 & 0 & 6.2 & 10.0 & 552 & 3.58 \\
20 & HFC-125 & 0 & 13.5 & 9.8 & & \\
25 & HFC-125 & 1.03 & 11.3 & -4.4 & 0 & 0.41
\end{tabular}

\section{BACKGROUND}

Enhanced combustion in the presence of fire suppressants has been observed in previous work. In experiments with high-speed turbulent flames in a detonation/deflagration tube, Grosshandler and Gmurczyk [4-7] observed more vigorous combustion with $\mathrm{CF}_{3} \mathrm{I}$ or $\mathrm{CF}_{3} \mathrm{Br}$, or various hydrofluorocarbon inhibitors, while using either propane or ethylene as fuels. For some conditions, the premixed addition of the halogenated agent to the air stream increased both the deflagration/shock propagation rate and the pressure ratio across the shock. The results varied with fuel type, stoichiometry, agent type, and the presence or absence of turbulence-inducing spirals. In tests with a constant volume, closed vessel combustion device, Shebeko et al. [8] found that various fluorinated inhibitors can enhance the combustion, creating both higher final pressures as well as higher rates of pressure rise, for hydrogen- or methane-air mixtures, under fuel-lean conditions. In shock heated mixtures of fuel, oxygen and argon, Moriwaki and co-workers [9-12] found that halomethanes $\left(\mathrm{CH}_{3} \mathrm{Cl}, \mathrm{CH}_{3} \mathrm{Br}, \mathrm{CH}_{3} \mathrm{I}\right)$, as well as $\mathrm{CF}_{3} \mathrm{Br}$, promote methane ignition (i.e., lower the ignition delay), but inhibit ethane ignition. Ikeda and Mackie [13] found that $\mathrm{C}_{3} \mathrm{HF}_{7}$ (2H-heptafluoropropane, HFC-227ea) added to shock-heated ethane-oxygen-argon mixtures at volume fractions up to 0.13 of the ethane concentration had little effect on the ignition times (with perhaps some acceleration effect) for near-stoichiometric conditions, while for somewhat higher amounts (39\% of the ethane concentration) and richer conditions $(\phi=1.5)$, there was some inhibition of the ignition (but much less than with added $\mathrm{CF}_{3} \mathrm{Br}$ ). Mawhinney et al. [14] found that unwanted accelerated burning could be caused by application of water mist to a fire (due to fluid-dynamic enhancement of the burning). Hamins et al. [15] reviewed previous work on enhanced burning with application of fire suppressants, and also concluded that the enhanced combustion was due to more rapid mixing of fuel vapor with air, from the combined effects of enhanced turbulent mixing and more vigorous liquid fuel atomization from agent jet impingement.

In other tests, halogenated hydrocarbons added to the air stream of diffusion flames have been shown to increase total heat release. Holmstedt et al. [16] reported that HFC 227ea or HFC 134a added to the fuel 
(propane) stream of a turbulent jet burner increased the total heat release, by a factor of 2 and 3.8 , respectively, for concentrations just below that required for extinguishment of the flame. Similarly, Katta et al. [17] found that $\mathrm{CF}_{3} \mathrm{H}$ added to the oxidizer stream in a methane-air cup-burner experiment increased the total heat release.

Based on previous work, it appears that higher overpressures in the FAA aerosol can tests might be due to higher heat release from reaction of the inhibitor itself. On the other hand, the agents should reduce the overall reaction rate and hence inhibit the reaction (and heat release or pressure rise) [18,19]. To investigate the propensity for higher heat release, the thermodynamics of the mixtures in the FAA tests are investigated below.

\section{APPROACH}

\section{Calculation of Initial Conditions}

There are a few caveats in performing the thermodynamic equilibrium calculations for the conditions of the aerosol can test. For a usual premixed flame calculation, the reactants are mixed, so the exact composition is known. For a non-premixed flame (for example, a laminar diffusion flame), the usual assumption is that the reactants diffuse to the reaction zone in stoichiometric proportions. For the aerosol can tests, however, the transport of reactants to the main reaction zone where they are consumed is likely controlled by highly dynamic turbulent mixing rather than diffusion. Also, the inhibitor species itself (which is added to the air stream) can act like a fuel species, with its own oxygen demand. Hence, some assumptions must be made concerning the relative amount each of the initial reactants in the equilibrium calculation. Since the fuel species (from the aerosol can contents) are premixed, and they are released explosively from their container, they are all included as reactants in their supplied proportions. For the oxidizer, the water vapor and inhibitor (if any) are assumed to be included at a fixed proportion in the "oxidizer" gases initially in the chamber. Since it is difficult to estimate the amount of oxidizer which interacts with the fireball during the explosive burning process, we allow that to be a variable in our calculations, expressed as $\eta$, the fraction of chamber oxidizer (air + agent + ambient water vapor) involved in the combustion. Likewise, we perform the calculations for a range of inhibitor volume fraction in the oxidizer, since agent can be present at any concentration depending upon system design and performance.

For the initial conditions, the fuel was taken to be the contents of the aerosol can simulator in the FAA tests of Reinhardt [2] (5.87 moles of ethanol, 2.05 moles of propane, and 5 moles of liquid water), and these were constant for all calculations (i.e., all of the fuel was assumed to be consumed). For the air in the chamber, oxygen and nitrogen at the volume fractions of 0.21 and 0.79 was assumed. Water vapor can affect both the equilibrium conditions of the mixture (as well as the kinetics) since the combustion behavior of hydrocarbon-air systems with added halogenated hydrocarbons are very sensitive to the overall hydrogen-to-halogen atom ratio in the mixture [20-22]. Relative humidity of the test air was not reported in the FAA tests; however, analysis of local weather data for the days of the tests indicates that water vapor volume fractions near $0.0125\left(50 \%\right.$ R.H. at $\left.21{ }^{\circ} \mathrm{C}\right)$ are typical. Hence, the equilibrium calculations were performed for a water vapor volume fraction of $0,0.0125$, and 0.025 in the $\mathrm{O}_{2} / \mathrm{N}_{2} / \mathrm{H}_{2} \mathrm{O}$ oxidizer mix.

Both the equilibrium thermodynamics and chemical kinetics of hydrocarbon systems with added halogens are highly sensitive to the overall halogen-to-hydrogen atom $[\mathrm{X}] /[\mathrm{H}]$ ratio (in which $\mathrm{X}$ is $\mathrm{F}, \mathrm{Br}$, or $\mathrm{Cl}$ ) $[22,23]$; hence, determining the conditions for which the $[\mathrm{X}] /[\mathrm{H}]$ ratio is unity is a first step (because the behavior above and below this values is expected to differ). It is also the only concentration for which calculation of the stoichiometric air requirement is straightforward. The procedure for determining the inhibitor volume fraction in the oxidizer stream, $X_{i}$, for which $[\mathrm{X}] /[\mathrm{H}]=1,\left.X_{i}\right|_{X / H=1}$, is outlined below.

Starting with a stoichiometric reaction of the fuel (with arbitrary ratio of $\mathrm{C}-\mathrm{H}-\mathrm{O}$ ) to the most stable products, $\mathrm{CO}_{2}$ and $\mathrm{HF}$ (which we can do since $[\mathrm{X}] /[\mathrm{H}]=1$ by definition, and $\mathrm{HF}$ is a more stable product of $\mathrm{H}$ than $\mathrm{H}_{2} \mathrm{O}$ ) yields:

$\varphi C_{a} H_{b} O_{c}+\gamma\left[\alpha C_{d} H_{e} F_{f}+\rho H_{2} O+O_{2}+\left(1 / X_{O_{2}}-1\right) N_{2}\right]=>\beta C O_{2}+\lambda H F+\gamma\left(1 / X_{O_{2}}-1\right) N_{2}$

Performing atom balances on $\mathrm{C}, \mathrm{H}, \mathrm{F}$, and $\mathrm{O}$, with the fuel-air equivalence ratio $\phi=1$, yields: 


$$
\begin{aligned}
& \alpha=\frac{[2 \rho(c-2 \mathrm{a}-b / 2)-2 \mathrm{~b}]}{[(f-e)(c-2 \mathrm{a})-2 b d]}, \quad \gamma=\frac{b}{\alpha(f-e)-2 \rho}, \quad \rho=\frac{X_{w v}}{\left(1-X_{w v}\right)}\left(\frac{1}{X_{O_{2}}}\right), \quad \text { and } \\
& X_{i}=\frac{\alpha}{\left(1+\frac{X_{w v}}{\left(1-X_{w v}\right)}\right) \frac{1}{X_{O_{2}}}+\alpha},
\end{aligned}
$$

in which $X_{O 2}$ is the oxygen volume fraction in the nitrogen and oxygen making up the air (typically 0.21 ), $X_{w v}$ is the volume fraction of water vapor in the air (before agent addition), and $X_{i}$ is the volume fraction of agent (inhibitor) in the oxidizer mixture (containing $\mathrm{N}_{2}, \mathrm{O}_{2}, \mathrm{H}_{2} \mathrm{O}$, and agent).

In the absence of inhibitor, $\alpha=0$ and $X_{i}=0$, and the stoichiometric relationship is:

$$
C_{a} H_{b} O_{c}+\gamma\left[\rho H_{2} O+O_{2}+\left(1 / X_{O_{2}}-1\right) N_{2}\right]=>\beta C O_{2}+\lambda H_{2} O+\gamma\left(1 / X_{O_{2}}-1\right) N_{2}
$$

from which $\gamma$ is found (from an atom balance on $\mathrm{C}, \mathrm{H}$, and $\mathrm{O}$, with $\phi=1$ ) to be:

$$
\gamma=a+b / 4-c / 2
$$

For the given fuel mixture in the aerosol can test, $a, b$, and $c$ are given as 17.87, 61.62, and 10.87 for one mole of equivalent fuel $\left(\mathrm{C}_{a} \mathrm{H}_{b} \mathrm{O}_{c}\right)$; i.e., the contents of the aerosol can simulator, described here as one mole of equivalent fuel: $\mathrm{C}_{17.87} \mathrm{H}_{61.62} \mathrm{O}_{10.87}$. (Note that this "equivalent" fuel is used only for the stoichiometry calculations; for the equilibrium calculations themselves, the actual component molecules in their correct proportions are used.) For the agents $\mathrm{C}_{2} \mathrm{HF}_{5}, \mathrm{C}_{3} \mathrm{H}_{2} \mathrm{~F}_{3} \mathrm{Br}$ (2-BTP), and $\mathrm{CF}_{3} \mathrm{Br}$, (d, e, and $\mathrm{f}$ ) are given as: $(2,1,5),(3,2,4)$, and $(1,0,4)$, respectively, for the agent written as $C_{d} H_{e} X_{f}$. The water vapor in the air specifies $X_{w v}$, yielding $\rho$, from which the oxidizer/fuel molar ratio, $\gamma$, is readily found. The number of moles of agent in the oxidizer $\alpha$, is also found, leading to $\left.X_{i}\right|_{X / H=l}$, the volume fraction of agent in the oxidizer stream when $[\mathrm{X}] /[\mathrm{H}]=1$. The relevant values of these parameters and the resulting number of moles (and mole fractions) in the reactant mix for $[\mathrm{X}] /[\mathrm{H}]=1$ are listed in Table 2 for no agent, $\mathrm{C}_{2} \mathrm{HF}_{5}$, $\mathrm{C}_{3} \mathrm{H}_{2} \mathrm{~F}_{3} \mathrm{Br}$, and $\mathrm{CF}_{3} \mathrm{Br}$. Calculations were performed for values of the relative humidity of the starting air of $0 \%, 50 \%$ and $100 \%$ at a chamber fill temperature of $21{ }^{\circ} \mathrm{C}$.

The data in Table 2 represent only those conditions for which $[\mathrm{X}] /[\mathrm{H}]=1$. In practice, the conditions can vary widely around these, with either much lower amounts of agent added, or even with higher amounts added. Usually, the results of equilibrium calculations are given in terms of the equivalence ratio; however, doing so one must know the stoichiometric air requirement-which for this case will change as the amount of agent in the air changes, and as the equilibrium products change as $[\mathrm{X}] /[\mathrm{H}]$ changes. Hence, the calculations were performed for a range of inhibitor volume fractions, and for a range of $\eta$, the fraction of chamber air involved in the reaction with the aerosol can contents. That is, $\eta$ is an alternate way to present the air/fuel ratio, which also has a clear physical interpretation for the FAA aerosol can test configuration.

For the calculations for HFC-125, 2-BTP, and $\mathrm{CF}_{3} \mathrm{Br}, \eta$ was varied from 0.27 to $1.03,0.23$ to 1.37 , and 0.17 to 0.65 , respectively. For each agent, $\mathrm{HFC}-125,2-\mathrm{BTP}$, and $\mathrm{CF}_{3} \mathrm{Br}$, the initial inhibitor volume fraction in the oxidizer gases was varied from 0 to $14.4 \%, 5.9 \%$, and $11.2 \%$., which correspond to about $200 \%, 100 \%$, and $100 \%$ of value for which $[\mathrm{X}] /[\mathrm{H}]=1$, for each agent, respectively. For the cases of HFC-125 and 2-BTP, these values are close to the highest values used in the FAA tests [1]; conversely, for $\mathrm{CF}_{3} \mathrm{Br}$, the highest amount used in the experiments was $2.5 \%$, which is only about a fourth of that for which $[\mathrm{X}] /[\mathrm{H}]=1,11.2 \%$ as indicated in Table 1 . The reasons for these ranges are discussed below. 
Table 2. Aerosol can test stoichiometric composition of reactants for agent present at $[\mathrm{X}] /[\mathrm{H}]=1$.

Inhibitor

\begin{tabular}{|c|c|c|c|c|c|c|c|c|c|c|c|c|}
\hline \multirow[b]{2}{*}{ Relative Humidity (\%) } & \multicolumn{3}{|c|}{ None } & \multicolumn{3}{|c|}{$\mathrm{C}_{2} \mathrm{HF}_{5}$} & \multicolumn{3}{|c|}{$\mathrm{C}_{3} \mathrm{H}_{2} \mathrm{~F}_{3} \mathrm{Br}$} & \multicolumn{3}{|c|}{$\mathrm{CF}_{3} \mathrm{Br}$} \\
\hline & 0 & 50 & 100 & 0 & 50 & 100 & 0 & 50 & 100 & 0 & 50 & 100 \\
\hline$\rho$ & 0 & 0.061 & 0.122 & 0 & 0.061 & 0.122 & 0 & 0.061 & 0.122 & 0 & 0.061 & 0.122 \\
\hline$\alpha$ & & & & 0.356 & 0.376 & 0.395 & 0.294 & 0.310 & 0.326 & 0.553 & 0.584 & 0.614 \\
\hline$\gamma$ & 27.84 & 27.84 & 27.84 & 43.25 & 44.59 & 46.06 & 104.9 & 123.5 & 150.9 & 27.84 & 27.84 & 27.84 \\
\hline$X_{\mathrm{i}}$ & & & & 0.070 & 0.072 & 0.075 & 0.058 & 0.060 & 0.063 & 0.104 & 0.108 & 0.112 \\
\hline $\mathrm{X}_{\mathrm{i}}$ (suppression) & & & & & 0.135 & & & 0.06 & & & 0.038 & \\
\hline \multicolumn{13}{|c|}{ Oxidizer Species (moles) } \\
\hline $\mathrm{O}_{2}$ & 5.85 & 5.85 & 5.85 & 9.08 & 9.36 & 9.67 & 22.02 & 25.94 & 31.69 & 5.85 & 5.85 & 5.85 \\
\hline $\mathrm{N}_{2}$ & 104.7 & 104.7 & 104.7 & 162.7 & 167.7 & 173.3 & 394.5 & 464.6 & 567.7 & 104.7 & 104.7 & 104.7 \\
\hline $\mathrm{H}_{2} \mathrm{O}(\mathrm{g})$ & 0.00 & 1.70 & 3.40 & 0.00 & 2.72 & 5.62 & 0.00 & 7.53 & 18.41 & 0.00 & 1.70 & 3.40 \\
\hline Agent & & & & 15.40 & 16.75 & 18.19 & 30.83 & 38.26 & 49.19 & 15.40 & 16.24 & 17.09 \\
\hline Total (oxidizer) & 110.6 & 112.3 & 114.0 & 187.2 & 196.6 & 206.8 & 447.4 & 536.3 & 667.0 & 126.0 & 128.5 & 131.1 \\
\hline Fraction of Chamber V & 0.23 & 0.24 & 0.24 & 0.40 & 0.42 & 0.44 & 0.95 & 1.13 & 1.41 & 0.27 & 0.27 & 0.28 \\
\hline \multicolumn{13}{|l|}{ Fuel Species (moles): } \\
\hline $\mathrm{C}_{2} \mathrm{H}_{5} \mathrm{OH}$ & 5.87 & 5.87 & 5.87 & 5.87 & 5.87 & 5.87 & 5.87 & 5.87 & 5.87 & 5.87 & 5.87 & 5.87 \\
\hline $\mathrm{C}_{3} \mathrm{H}_{8}$ & 2.05 & 2.05 & 2.05 & 2.05 & 2.05 & 2.05 & 2.05 & 2.05 & 2.05 & 2.05 & 2.05 & 2.05 \\
\hline $\mathrm{H}_{2} \mathrm{O}(\mathrm{L})$ & 5 & 5 & 5 & 5 & 5 & 5 & 5 & 5 & 5 & 5 & 5 & 5 \\
\hline Total Moles (all): & 123.5 & 125.2 & 126.9 & 200.1 & 209.5 & 219.7 & 460.3 & 549.2 & 679.9 & 138.9 & 141.4 & 144.0 \\
\hline
\end{tabular}

\section{Equilibrium Calculations}

The equilibrium composition, temperature, and pressure for a mixture of gases at some given initial state can be calculated $[24,25]$. Automated numerical techniques are available, which use the method based on minimizing the Gibbs free energy, for a large number of species typically present in combustion systems. The equilibrium conditions of the aerosol can test were calculated using both the STANJAN-III program of Reynolds [26], and CEA2 of Gordon and McBride [27]. The calculations were performed over a wide range of initial conditions as described above.

The numerical calculations provide data on the equilibrium composition (i.e., species mole fractions), entropy, enthalpy, temperature, and pressure of the final mixture - for the gases involved in the reaction. In principle, such calculations can be used to determine the pressure rise in the FAA chamber since reaction of the fuel, air, and inhibitor cause energy release which leads to a pressure (or volume) and temperature rise (depending upon whether pressure/enthalpy (HP) or volume/internal energy (UV) are held constant). As discussed above, such a calculation is straightforward if one knows the initial composition of the reactants (i.e., a premixed system). For a turbulently mixing system, as in the aerosol can test, the amount of oxidizer involved in the combustion depends upon the mixing, and is not known a priori. Hence, we include $\eta$ as a variable parameter, and examine its effect on the equilibrium predictions. As with any fuel/oxidizer system, it is necessary to determine what fraction of the possible oxidizer gases in the chamber volume are actually involved in the high temperature (i.e., rapid) reaction with the fuel. For a typical premixed hydrocarbon-air mixtures, when doing a constant $\mathrm{U}, \mathrm{V}$ calculation for a fixed chamber [air] mass with a fixed [hydrocarbon] fuel mass, the pressure rise would depend upon what fraction of the air is included in the equilibrium calculation (i.e., $\phi$ ); for $\phi<1$, the dilution lowers the temperature, and also changes the equilibrium products (due to lower temperature). For the case of air premixed with agent, however, selecting the fraction of the chamber air involved in the high-temperature reaction is even more important, because the inhibiting agent itself has a high energy content, but is unlikely to react by itself without the interaction 
with a flame. That is, the inhibitor can react to its most stable products and release energy, but is only likely to do so if it interacts with the high-temperature fire ball.

\section{Pressure Rise Calculations}

The following procedure was used to determine the final pressure in the chamber. The fuel from the aerosol can simulator was fixed as specified above. The amount of water vapor and agent in the premixed chamber gases was specified, along with the initial pressure and temperature (typically 1 bar and $21^{\circ} \mathrm{C}$ ). Next, the fraction of chamber gases to interact with the expanding fire ball was specified (from which the mass of chamber gases not involved in the combustion was also specified). For the total involved mass (propane/ethanol/water in the aerosol can; plus the oxygen, water vapor, nitrogen, and agent in the involved chamber volume), a constant $\mathrm{H}$, constant $\mathrm{P}$ equilibrium calculation was performed to determine the conditions after complete reaction. This specified the final volume of the involved reactants, which was added to the volume of the uninvolved gases, to yield a total final volume. Finally, the ideal gas law was used to find the pressure rise from this volume change, had the volume remained constant (i.e., $\left.\mathrm{V}_{\mathrm{f}} / \mathrm{V}_{\mathrm{i}}=\mathrm{P}_{\mathrm{f}} / \mathrm{P}_{\mathrm{i}}\right)$. Heat losses are neglected since the duration of the event is short $(\sim 1 \mathrm{~s})$ and flame interaction with the walls is delayed because of the large volume. Nonetheless, inclusion of heat losses would lower the final pressure.

\section{RESULTS AND DISCUSSION}

\section{Stoichiometric Reaction}

The initial conditions for stoichiometric reaction of the aerosol can test fuel with air are described above. Referring to Table 2 and considering the cases for where $X_{w v}=0.0125(50 \% \mathrm{RH})$, the stoichiometric air requirement, $\gamma$, for the case of no agent is 27.8 moles of oxygen/mole of equivalent fuel, which corresponds to a total oxidizer requirement of 112.3 moles. Since the volume of the chamber is $11400 \mathrm{~L}$ ( 473 moles at $21{ }^{\circ} \mathrm{C}$, and $1.01 \mathrm{bar}$ ), the stoichiometric consumption of the aerosol can fuel mix requires $24 \%$ of the chamber volume. Adding the chemical suppressant $\left(\mathrm{C}_{2} \mathrm{HF}_{5}, \mathrm{C}_{3} \mathrm{H}_{2} \mathrm{~F}_{3} \mathrm{Br}\right.$, or $\left.\mathrm{CF}_{3} \mathrm{Br}\right)$ to the air stream increases the fraction of the chamber air, $\eta$, required for stoichiometric combustion. A variation in the relative humidity can have a marked influence on both $X_{i}$ and $\eta$ (with range of variation given by the following errors). Table 2 shows that the condition of unity $[\mathrm{X}] /[\mathrm{H}],\left.X_{i}\right|_{X / H=1}$, is $0.072 \pm 0.0025,0.06 \pm 0.0025$, and $0.108 \pm 0.004$, for $\mathrm{C}_{2} \mathrm{HF}_{5}, 2-\mathrm{BTP}$, and $\mathrm{CF}_{3} \mathrm{Br}$, respectively, while $\eta$ is $0.42 \pm 0.025,1.13 \pm 0.21$, and $0.27 \pm$ 0.005 . For reference, it should be recalled that suppression of the explosion requires $X_{i}=0.135,0.06$, and 0.04 for, HFC-125, 2-BTP, and $\mathrm{CF}_{3} \mathrm{Br}$, and these numbers are $200 \%, 100 \%$, and $37 \%$ of the value for which $[\mathrm{X}] /[\mathrm{H}]=1$.

The first thing to notice for HFC-125 is that unlike other flame conditions, for which the flames tend not to burn above $\left.X_{i}\right|_{X / H=1}$ [20-22], suppressing the aerosol can test required $X_{i}$ twice the value of $\left.X_{i}\right|_{X / H=I}$. Under that condition, the system should be severely $\mathrm{H}$-atom limited. For 2-BTP, the value of $X_{i}$ for which $[\mathrm{X}] /[\mathrm{H}]=1,\left.X_{i}\right|_{X / H=1}$ is around 0.06 . Referring to Table 1 , the FAA tests were conducted up to $X_{i}=0.06$, but extinguishing concentrations of 2-BTP were not achieved. An important result of this is that for all of the FAA experiments with 2-BTP (i.e., up to $X_{i}=0.06$ ), the system is never hydrogen limited. Nonetheless, varying the relative humidity between $0 \%$ and $100 \%$ has about a $4 \%$ effect on $\left.X_{i}\right|_{X / H=I}$ for all the agents, and about a $4 \%$ effect on $\eta$ for $\mathrm{C}_{2} \mathrm{HF}_{5}$ and $\mathrm{CF}_{3} \mathrm{Br}$, but a $20 \%$ effect on $\eta$ for 2-BTP. Hence, the pressure rise with 2-BTP may be very sensitive to the relative humidity in the test air.

The results presented here are for stoichiometric combustion to the most stable products (at $[\mathrm{X}] /[\mathrm{H}]=1$ ). For more generality, they must be substantiated through complete thermodynamic equilibrium calculations for the full range of inhibitor volume fractions $X_{i}$ and fractions of chamber air reacting $\eta$.

As described above, once the fraction of chamber air involved in the combustion is specified, the adiabatic flame temperature can be used to estimate the pressure rise for complete reaction of the involved species to equilibrium products. The results of these calculations, together with the adiabatic flame temperature calculations, are presented below for $\mathrm{HFC}-125,2-\mathrm{BTP}$, and $\mathrm{CF}_{3} \mathrm{Br}$, for the range of $X_{i}$ and $\eta$ used above. 


\section{Adiabatic Flame Temperatures and Pressure Rise}

Comprehensive equilibrium calculations for the aerosol can test fuel, for a specified fraction of the chamber volume of oxidizer, and for a specified value of $X_{i}$ can illustrate: i) the effect of formation of minor species on the final temperature and air requirement, and ii) the oxidizer (air and agent) faction which gives the most favorable consumption of the fuel (for values of $X_{i}$ away from $\left.X_{i}\right|_{X / H=1}$, as is the case in Table 2.) From these, the pressure rise is calculated for the full range of conditions.

HFC- 125

Figure 1a shows the final temperature (of the gases involved in the combustion) in the aerosol can test as a function of the fraction of chamber air involved in the combustion, $\eta$. The different curves represents initial volume fractions of HFC-125 in the chamber gases, ranging from $X_{i}=0$ to 0.144 (in equal increments). As indicated, the final temperature reaches a peak at one value of $\eta$, and then drops off for more or less oxidizer. Note that Fig. 1a shows the final temperature of only the involved gases; for those cases with $\eta$ less than 1, the final temperature of all the [mixed] gases would be lower due to dilution. The curves for lower values of $X_{i}$ (less than $8 \%$ ) follow the typical variation in adiabatic flame temperature with fuel-air equivalence ratio, $\phi$ [24], and the peak values are near $2140 \mathrm{~K}$. For $X_{i}>0.08$, the peak temperature drops significantly, and for a given value of $X_{i}$, the variation in the peak temperature with $\eta$ is milder. Figure $1 \mathrm{~b}$ shows the peak temperature (for any value of $\eta$ ) as a function $X_{i}$, and the value of $\eta$ for which the peak occurs. As indicated, as $X_{i}$ increases above $\left.X_{i}\right|_{X / H=l}(0.072)$, the peak temperature drops more steeply, and the fraction of vessel air at the peak temperature also increases more rapidly. The last few points of the curve for $\eta$ in Fig. 1b show that the required $\eta$ for peak temperature is greater than one. The change in behavior when $X_{i}>\left.X_{i}\right|_{X / H=1}$ occurs since the increasing $[\mathrm{X}] /[\mathrm{H}]$ ratio in the system changes the equilibrium products; for example, $\mathrm{COF}_{2}$ formation increases, decreasing the final temperature [19,28].

The chamber pressure rise in the aerosol can test with added HFC-125 is shown in Fig. 2a, in which, like Fig. 1a, each curve corresponds to a different value of $X_{i}$. As shown in Fig. 2a, allowing more vessel air to participate always increases the pressure rise. The kink in each of the curves, where the slope changes, represents the value of $\eta$ for the peak temperature. Clearly, it is necessary to know the actual value of $\eta$ to accurately estimate the pressure rise.

While a more detailed knowledge of the mixing processes occurring during the aerosol can test is desirable, there still exist various ways to estimate $\eta$. In a laminar diffusion flame, the flame location between the oxidizer and fuel streams typically occurs near the location where the oxidizer and fuel diffuse together in stoichiometric proportions. This is near to the location of peak temperature. Hence, Fig. $2 b$ shows the final chamber pressure at the value of $\eta$ which yields the peak temperature ( $\Delta$ symbols). Other criteria are possible. For example, in a hydrocarbon-air system, the location of peak $\mathrm{CO}_{2}$ is typically near to the flame sheet; hence, Fig. $2 \mathrm{~b}$ also shows the pressure rise based on $\eta$ of peak $\mathrm{CO}_{2}$ ( $\square$ symbols). For an adiabatic reaction system with variable stoichiometry, the value of $\phi$ for which the [CO] starts to increase appreciably is near to the stoichiometric ratio (since $\mathrm{CO}$ formation reduces the final temperature, and hence, the overall reaction rate). Likewise, for a system with halogen and hydrogen (e.g., halogen-inhibited hydrocarbon flames), the reaction rate is much higher if halogen and hydrogen come together in their desired proportions (i.e., sufficient hydrogen). Reaction is highly favored in regions where the production of $\mathrm{COF}_{2}$ is not occurring, since presence of this species typically signifies much lower $\mathrm{H}$ atom concentrations [22,23]. For HFC-125, $\mathrm{COF}_{2}$ forms in appreciable concentrations only for $X_{i}>0.072$. To explore kinetic effects of $\mathrm{CO}$ or $\mathrm{COF}_{2}$ formation, Fig. $2 \mathrm{~b}$ also shows a curve corresponding to the pressure rise when the value of $\eta$ is based the fraction of product-species carbon in $\mathrm{CO},[\mathrm{CO}] /\left([\mathrm{CO}]+\left[\mathrm{CO}_{2}\right]\right)=0.001$ ( $\times$ symbols), as well as the fraction fluorine in showing up as $\mathrm{COF}_{2}, 2\left[\mathrm{COF}_{2}\right] /\left(2\left[\mathrm{COF}_{2}\right]+[\mathrm{HF}]\right)=0.01(\Delta$ symbols). That is, the flame will prefer to exist where the formation of either $\mathrm{CO}$ or $\mathrm{COF}_{2}$ is minimized. These latter two criteria inject a kinetic argument into the thermodynamic estimates (which is also reasonable since the temperature peak is very flat). To include both effects simultaneously, the mean of these two curves is plotted (+ symbols) in Fig. $2 \mathrm{~b}$. This last curve captures the magnitude and the trend of the experimental data quite well. As shown in Fig. $2 b$, any of these criteria for specifying $\eta$ : peak $\mathrm{T}$, peak $\mathrm{CO}_{2}$, or average of minimizing $\mathrm{CO}$ or $\mathrm{COF}_{2}$ formation, predicts the pressure rise well (especially considering the complexity of the phenomena occurring in the experiment and the present simplifications). 


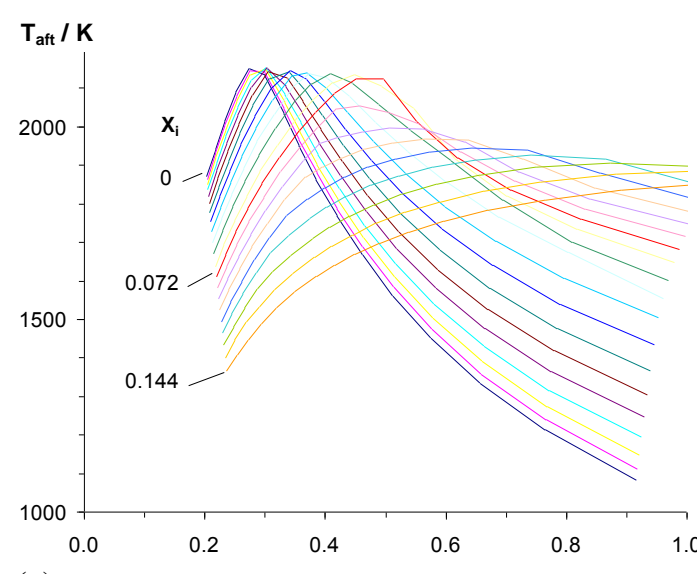

(a) Fraction of Chamber Volume Involved in Combustion, $\eta$

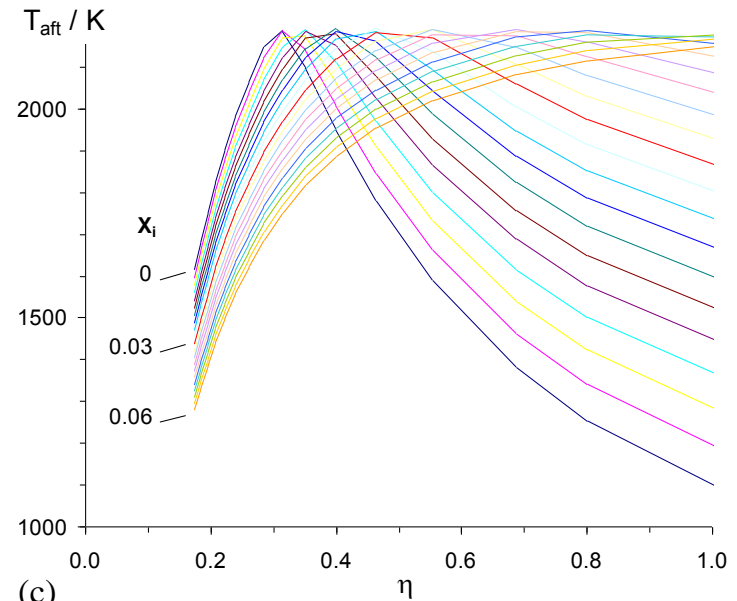

(c)

$\mathrm{T}_{\text {aft }} / \mathrm{K}$

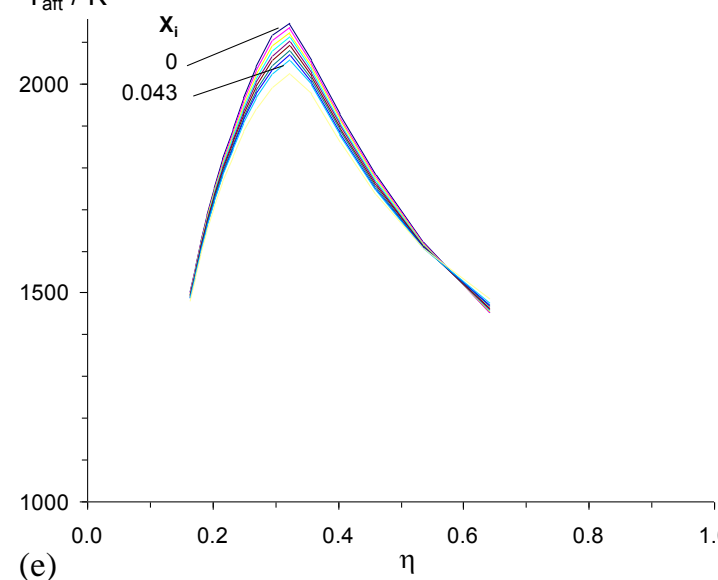

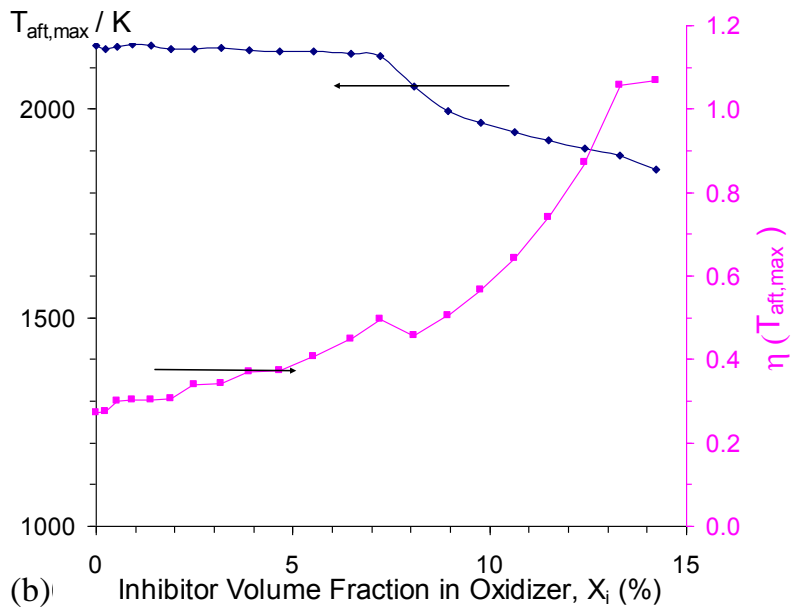

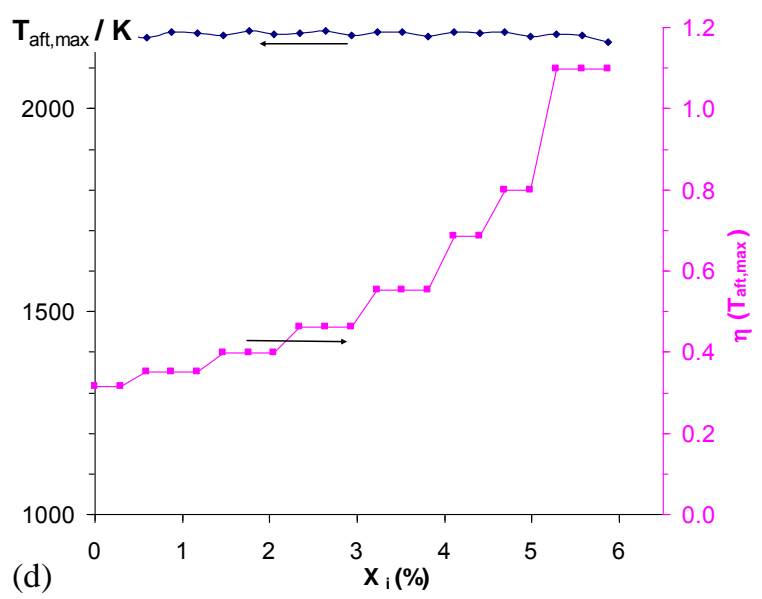

(d)

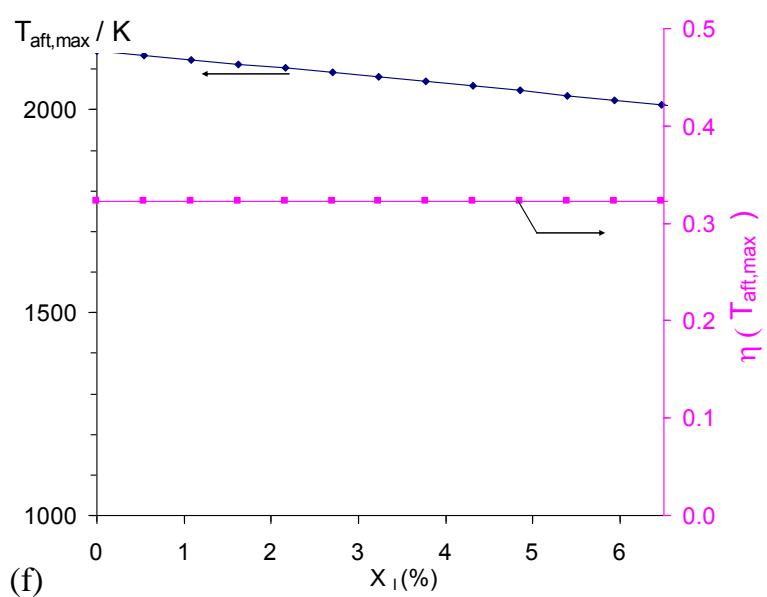

Fig. 1. Left frames: predicted adiabatic flame temperature (of the involved gases) in the FAA Aerosol Can Test [1] as a function of fraction test chamber volume involved in the reaction, $\eta$; different curves on each frame show different values for the inhibitor volume fraction in the oxidizer, $X_{i}$ : (a) HFC-125; (c) 2-BTP; (e) $\mathrm{CF}_{3} \mathrm{Br}$. From these plots, (b), (d) and (f) show the peak $T_{a f t}$ for any value of $\eta$, and the value of $\eta$ for which it occurs. 


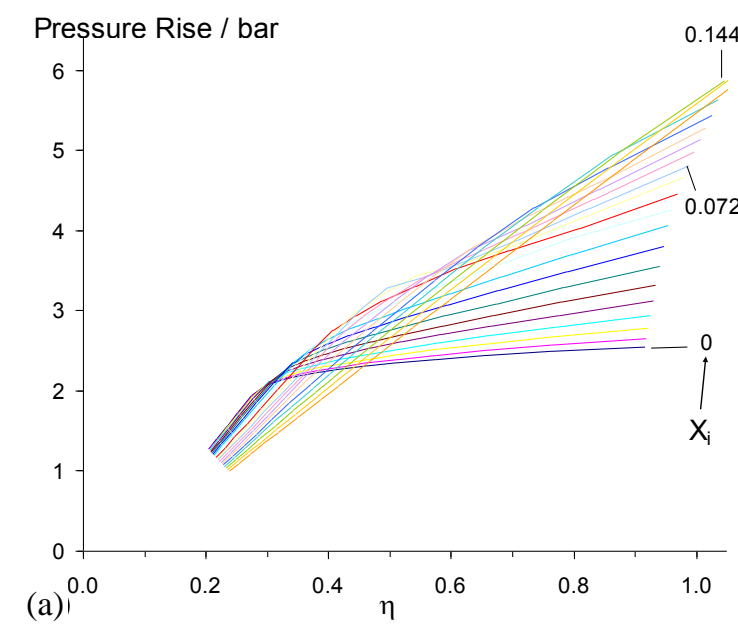

Pressure Rise at $\eta\left\{y_{\text {peak }}\right\}$ / bar

(a) ${ }^{\circ}$
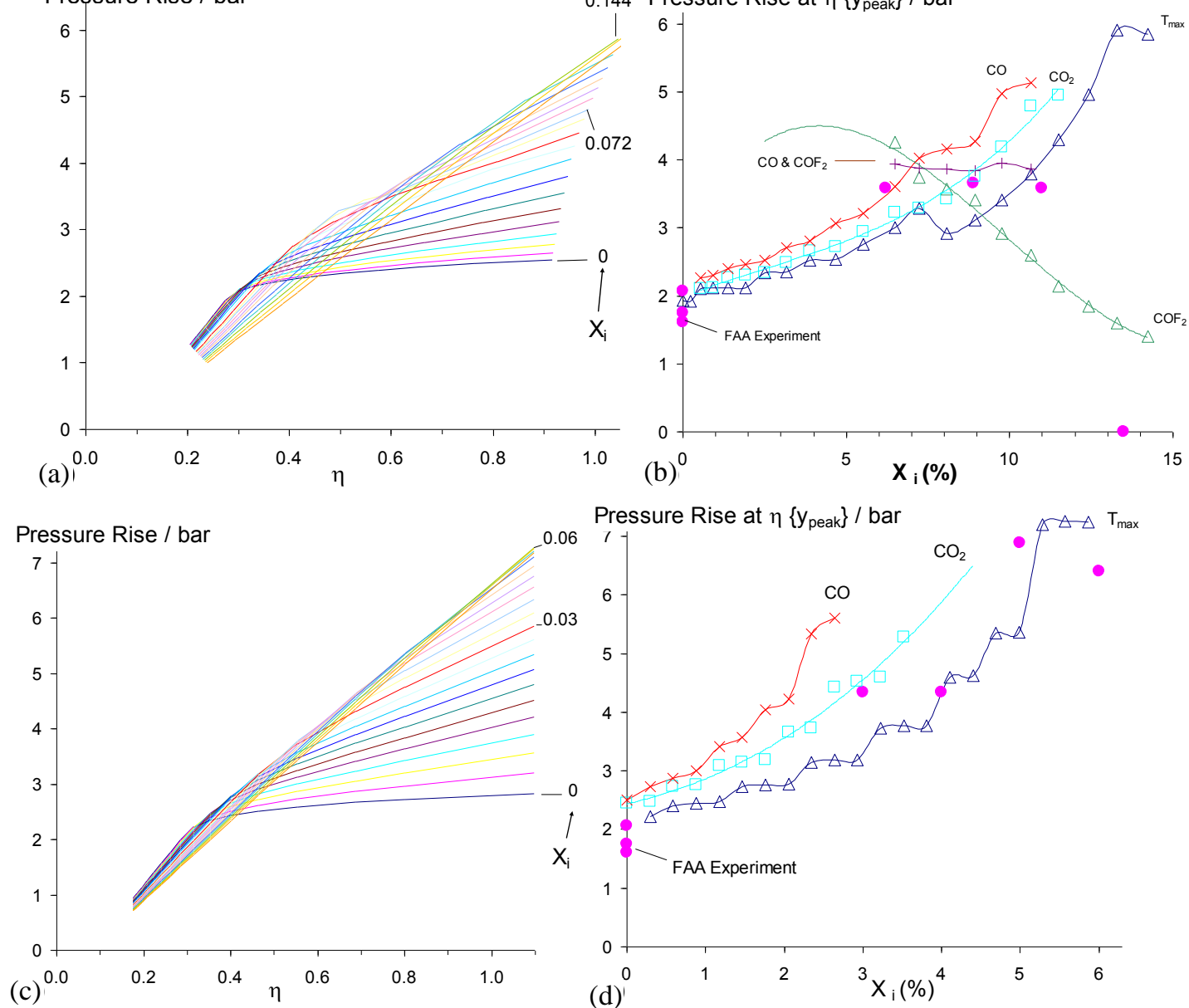

(c)
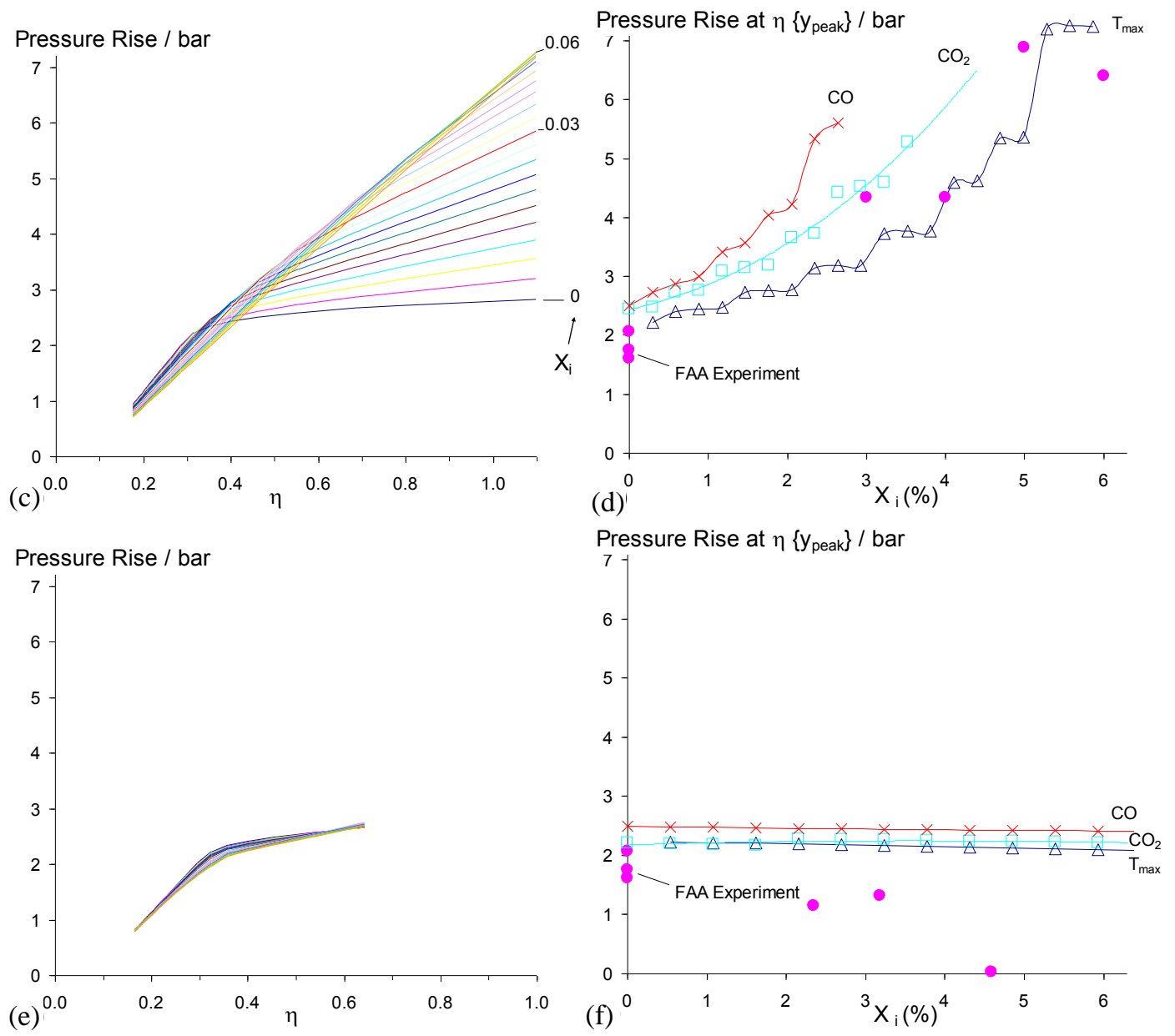

Fig. 2. Left frames: predicted pressure rise in the FAA Aerosol Can Test [1] as a function of fraction of chamber volume involved in the reaction, $\eta$, different curves show different values for the inhibitor volume fraction in the oxidizer, $X_{i}$ : (a) HFC-125; (c) 2-BTP; (e) $\mathrm{CF}_{3} \mathrm{Br}$. From these data, (b), (d) and (f) show the peak pressure rise evaluated at $\eta$ of peak $T_{a f t}$, peak $\mathrm{CO}_{2}, \mathrm{CO}$ fraction above 0.001 , and $\mathrm{COF}_{2}$ fraction above 0.01, and the mean of the last two; solid circles are the FAA experimental data. 
As described above, for values of $X_{i}$ above $\left.X_{i}\right|_{X / H=1},\left(0.072\right.$ for HFC-125), the variation in $T_{a f t}$ in Fig. 1a with $\eta$ is very mild (when $\eta$ is near that of peak temperature). For example, with $11.2 \%$ HFC- 125 , values of $\eta$ from 0.5 to 0.97 produce final temperatures within $100 \mathrm{~K}$ of the peak value. As shown in Fig. 1a above, these values of $\eta$ imply a pressures rise of $3 \mathrm{bar}$ to $5.5 \mathrm{bar}$, as compared to $3.7 \mathrm{bar}$ in the experiment. Finally, the pressure rise is not predicted well for $X_{i}=0.135$, for which the extent of reaction is zero (suppression of the explosion). In this case, kinetic calculations will be necessary to understand the reduction in the overall reaction rate with addition of inhibitor.

\section{2-BTP}

Similar thermodynamic equilibrium calculations to those performed for HFC-125 discussed above were performed for 2-BTP, and the results are shown in Fig. 1c, which shows the temperature of the involved gases as a function $\eta$, with each curve corresponding to a fixed value of $X_{i}$ (ranging from 0.001 to 0.06 ). Figure $1 \mathrm{~d}$ shows the peak temperature (for any value of $\eta$ ) as a function $X_{i}$ for 2-BTP, and the value of $\eta$ for which the peak occurs. Unlike the case of HFC-125, the peak temperature with added 2-BTP is nearly constant (since for 2-BTP, $X_{i}<\left.X_{i}\right|_{X / H=1}$ ). Like the HFC-125 case, as $X_{i}$ increases, $\eta$ at the peak temperature increases exponentially. The last few points of the peak temperature curve in Fig. $1 \mathrm{~d}\left(0.055<=X_{i}<=0.06\right)$ drop off because insufficient oxidizer is available in the chamber. Interestingly, for both HFC-125 and 2BTP, the last value of $X_{i}$ for which data was collected in the FAA test, has a value of $\eta$ greater than unity (only results for $\eta$ up to 1.10 were calculated here; the actual values of $\eta_{\text {peak }}$ would clearly be higher).

The qualitative shapes of the temperature curves for 2-BTP and HFC-125 are the same: the curve for no agent drops off rapidly as $\eta$ moves from its value at the peak; whereas at higher agent loadings, large variations in $\eta$ produce very little change in the peak temperature.

The pressure rise predicted based on equilibrium thermodynamics for added 2-BTP in the FAA aerosol can test is shown in Fig. 2c. As indicated, pressure rises of up to 4 times that without agent are predicted. Adding inhibitor increases the pressure rise for all values of $\eta$. As with HFC-125, the kinks in the curves correspond to the values of $\eta$ for the peak temperature, and this condition requires more chamber oxidizer (higher $\eta$ ) as the amount of inhibitor in the oxidizer increase (higher $X_{i}$ ). Figure $2 \mathrm{~d}$ shows the peak chamber pressure rise with added 2-BTP. Three criteria for specifying $\eta$ are used: that corresponding to peak temperature ( $\Delta$ symbols), peak $\mathrm{CO}_{2}$ ( $\square$ symbols), or start of the $\mathrm{CO}$ formation described above (x symbols) (the $\mathrm{COF}_{2}$ formation criterion is not applicable since $X_{i}<\left.X_{i}\right|_{X / H=1}$ ). As indicated in Fig. 2d, the peak $\mathrm{CO}_{2}$ or temperature criterion give good prediction of the pressure rise, and the agreement is very good considering the simplifications in the present analyses. For the case of $X_{i}=0.06$, the prediction is too high; as with HFC-125 at $X_{i}=0.135$, this may be the regime in which the kinetic rates are limiting the extent of reaction to less than unity. It should be noted that as described above, for 2-BTP, the amount of water vapor in the ambient air has a large effect on $\eta$ for the peak temperature, which has a large effect on the pressure rise. Hence, some of the difference between the predicted pressure rise and the experimental value may be due to differences in the ambient relative humidity (which was unrecorded, but varied from 0.33 to 0.63 at a local weather station during the day of the tests).

Finally, as described above for HFC-125, because the curves at high $X_{i}$ are very flat in Fig. 1c, the range of $\eta$ for which the temperature is near to the peak value is large, leading to a wide possible range of pressure rises according to the actual value of $\eta$. For example, at $X_{i}=0.047$, the peak temperature of the involved gases is $2171 \mathrm{~K}$, and values of $\eta$ from 0.57 to 1.00 have peak temperatures within $100 \mathrm{~K}$ of this value; for these values of $\eta$, the corresponding pressure rise is $3.7 \mathrm{bar}$ (53.6 psig) to $6.6 \mathrm{bar}$ (95.6 psig), and these compare with an interpolated experimental value of about 5.5 bar. That is, there is a wide range of $\eta$ values for which the temperature is near the peak, and these lead to a wider range of possible pressure rises.

\section{$\mathrm{CF}_{3} \mathrm{Br}$}

Halon 1301, even at sub-inerting concentrations, did not produce the over pressures characteristic of the tests with HFC-125 and 2-BTP [1]. Referring to Table 2, equal amounts of halogen and hydrogen in the system are achieved at $\left.X_{i}\right|_{X / H=1}=0.108$, which is much higher than either the levels tested in the FAA experiments noted in Table $1\left(X_{i}=0.025\right)$, or that were found to completely extinguish the aerosol can test 
explosion $\left(X_{i} \approx 0.037\right)$ [3]. Interestingly, the stoichiometric air requirement at $[\mathrm{X}] /[\mathrm{H}]=1$, expressed as the fraction of the chamber volume $\eta$, is only 0.27 , or about $10 \%$ higher than with no agent at all (0.24).

Figure 1e shows the adiabatic flame temperature of the involved gases with $\mathrm{CF}_{3} \mathrm{Br}$ premixed in the oxidizer stream, as a function of $\eta$, for different values of $X_{i}$. (ranging from 0.001 to 0.108 ). As indicated, the peak temperature occurs at $\eta=0.33$, and this value is independent of the value of $X_{i}$. This is in contrast to HFC125 and 2-BTP, for which added agent caused a propensity to involve more oxidizer, increasing $\eta$. The variation in $T_{a f t}$ with $X_{i}$ is greatest at $\eta$ of the peak temperature; whereas variation is small at higher or lower values of $\eta$. The peak $T_{a f t}$ for $\mathrm{CF}_{3} \mathrm{Br}$ is shown in Fig. 1f, together with the value of $\eta$ at the peak temperature. As indicated, the peak $T_{a f t}$ decreases as $\mathrm{CF}_{3} \mathrm{Br}$ is added, from $2171 \mathrm{~K}$ at $X_{i}=0$ to $1931 \mathrm{~K}$ at $X_{i}=0.11$; this decrease (up to $\left.X_{i}\right|_{X / H=1}$ ) is greater for $\mathrm{CF}_{3} \mathrm{Br}$ as compared to the other two agents (although for $\mathrm{CF}_{3} \mathrm{Br}, X_{i}$ of interest is about four times lower than $\left.\left.X_{i}\right|_{X / H=1}\right)$.

The predicted pressure rise with added $\mathrm{CF}_{3} \mathrm{Br}$ is shown in Fig. $2 \mathrm{f}$, for $\eta$ determined from the value for peak $T_{a f t}$ or $\left[\mathrm{CO}_{2}\right]$. As $X_{i}$ increases from 0 up to 0.108 , the pressure rise decreases slightly, from is 2.27 bar to 2 bar for $X_{i}=0$ to 0.108 (unlike HFC-125 and 2-BTP, for which the pressure rise always increases as agent is added). This difference is because, as indicated in Fig. 1e, the oxygen demand of the system with added $\mathrm{CF}_{3} \mathrm{Br}$ does not increase with increasing $\mathrm{CF}_{3} \mathrm{Br}$ in the oxidizer gases. The pressure rise decreases slightly because as shown in Fig. 1e, $T_{a f t}$ decreases with added $\mathrm{CF}_{3} \mathrm{Br}$. Another striking feature of the actual and predicted pressure rise for $\mathrm{CF}_{3} \mathrm{Br}$, is that the experimental value from the FAA tests drops steadily as agent is added. Clearly, the extent of reaction is getting lower for higher values of $X_{i}$, indicating kinetic inhibition.

There are several important observations to make from Fig. 1, for the agents HFC-125 and 2-BTP:

i.) For values of $X_{i}$ up to $\left.X_{i}\right|_{X / H=1}$, adding inhibitor does not appreciably lower the peak final temperature.

ii.) Even for $X_{i}$ above $\left.X_{i}\right|_{X / H=1}$ (e.g., HFC-125), if the reaction can proceed to the most thermodynamically favorable products, the peak temperature is still quite high (above $1865 \mathrm{~K})$.

iii.) For higher values of $X_{i}$, large fractions of the chamber volume are involved for stoichiometric combustion (based on $\eta$ for the peak temperature).

iv.) For values of $X_{i}$ above $\left.X_{i}\right|_{X / H=1}$, the temperature near the peak is very flat; that is, a wide range of values of $\eta$ (the fraction of chamber air involved) give nearly the same value of the peak temperature.

For the agent $\mathrm{CF}_{3} \mathrm{Br}$, the key features are that

i.) Adding agent does not require more chamber air to maintain peak $T_{a f f}$, and

ii.) At the extinguishing concentration (0.038), the $T_{a f t}$ drops only by around $100 \mathrm{~K}$ as compared to $X_{i}=0$.

iii.) The experimental pressure rise with added $\mathrm{CF}_{3} \mathrm{Br}$ is lower than predicted based on equilibrium thermodynamics (apparently, $\mathrm{CF}_{3} \mathrm{Br}$ provides kinetic inhibition at any value of $\left.X_{i}\right)$.

The presence of the agents HFC-125 and 2-BTP in the oxidizer (at the volume fraction required for unity hydrogen-to-halogen ratio) greatly increases the fraction of chamber gases required for stoichiometric combustion; whereas, $\mathrm{CF}_{3} \mathrm{Br}$ has no such effect. The unique behavior of $\mathrm{CF}_{3} \mathrm{Br}$ in this regard is explained as follows. The inhibitor molecules have both fuel and oxidizer properties: the halogens are oxidizing species, while the carbon and hydrogen are fuel (reducing) species. The most stable products for the halogens are the halogen acid, $\mathrm{HX}$, while for carbon, it is $\mathrm{CO}_{2}$. Since by definition, $[\mathrm{X}] /[\mathrm{H}]=1$, all of the halogen forms HX, and by definition (since $\alpha$ and $\gamma$ were free parameters) all carbon goes to $\mathrm{CO}_{2}$. When HFC-125 is present in the oxidizer at $7.2 \%$, adding oxidizer adds more oxygen to consume the fuel molecules, but also adds a fuel load from the HFC-125 in the air. The halogen molecules present in the HFC-125 combine either with the hydrogen in the HFC-125, the hydrogen in the water in the air, or the hydrogen in the fuel mix. On the other hand, the carbon in the HFC-125 needs the oxygen from the chamber gas, but adding chamber gas adds more HFC-125. The result is that the fraction of the chamber air required when HFC-125 is present in the air stream at $7.2 \%$ is almost doubled (as compared to the air requirement without HFC-125). This effect is stronger for 2-BTP since it has two hydrogen atoms and three 
carbon atoms, so that with added 2-BTP at $\left.X_{i}\right|_{X / H=1}$, the fraction of chamber air required is 4.7 times that without agent. In contrast, with added $\mathrm{CF}_{3} \mathrm{Br}$ at $[\mathrm{X}] /[\mathrm{H}]=1$, there is little added oxygen demand. For this particular chemical system (aerosol can test fuel, $\mathrm{O}_{2}, \mathrm{~N}_{2}$, water vapor, and $\mathrm{CF}_{3} \mathrm{Br}$ ), the atoms just balance so that, conceptually, all the water formed from reaction of the fuel molecule with the air forms water, which then supplies $\mathrm{H}$ and $\mathrm{O}$ in just the right proportion (2:1) to oxidize the $\mathrm{CX}_{4}$ to $\mathrm{CO}_{2}$ and $\mathrm{HX}$; e.g., $2 \mathrm{H}_{2} \mathrm{O}+$ $\mathrm{CF}_{3} \mathrm{Br} \Rightarrow \mathrm{CO}_{2}+3 \mathrm{HF}+\mathrm{HBr}$, with $T_{a f t}=985 \mathrm{~K}$. That is, there is always sufficient water from the fuel consumption to supply the $\mathrm{H}$ and $\mathrm{O}$ molecules for complete $\mathrm{CF}_{3} \mathrm{Br}$ reaction. With less $\mathrm{CF}_{3} \mathrm{Br}$ than that for $[\mathrm{X}] /[\mathrm{H}]=1$, there will just be extra $\mathrm{H}_{2} \mathrm{O}$ left over after all the $\mathrm{CF}_{3} \mathrm{Br}$ is consumed. The implication of this result is that if a molecule (or combination of compounds) can be found with the same $\mathrm{X} / \mathrm{C}$ ratio as $\mathrm{CF}_{3} \mathrm{Br}$ (for example, $\mathrm{CCl}_{4}, \mathrm{CF}_{4}$ ), it should not cause an increased pressure rise in the FAA aerosol can test under any circumstances.

\section{CONCLUSIONS}

Thermodynamic equilibrium calculations were performed in order to understand the anomalous and unwanted enhanced pressure rise for conditions of a simulated aerosol can explosion in an aircraft cargo bay, when certain fire suppressants are added. The calculations successfully predicted the pressure rise for a wide range of conditions. The calculations indicate that for the agents $\mathrm{C}_{2} \mathrm{HF}_{5}$ and $\mathrm{C}_{3} \mathrm{H}_{2} \mathrm{~F}_{3} \mathrm{Br}$, complete reaction of the fuel and agent, at a fuel-oxidizer ratio pertaining to peak temperature, is required to produce the pressure rise. As one of these agents is added to the oxidizer, the amount of oxidizer required increases geometrically, since the inhibitor itself has a significant oxygen requirement. Extent of reaction of unity is required to reproduce the observed pressure rise for all inhibitor concentrations except at the highest concentrations tested (13.5\% for HFC-125, and $6 \%$ for 2-BTP). At these concentrations, however, the overall system is oxygen limited, so any suppression effects may have been due to oxygen starvation (as opposed to the expected chemical inhibition). Conversely, $\mathrm{CF}_{3} \mathrm{Br}$ was found to cause no over-pressure enhancement for two reasons: 1) it reduces the extent of reaction at all concentrations, and 2) it does not increase the oxygen demand of the system. This latter effect is due to the unique stoichiometry of the system with added $\mathrm{CF}_{3} \mathrm{Br}$. With added HFC-125 or 2-BTP at high loading, variation in $T_{a f t}$ is very mild near the peak in $T_{a f t}$. Hence, energetically, there is a very wide range of $\phi$ over which the flame might burn. Additional research (e.g., chemical kinetic calculations) is suggested to explain the lack of expected chemical inhibition by the HFC compounds, as well as to explore the possibility of extinction by these HFCs only when the systems reach their rich limit or inerting concentration. The present results are of significance not only for fire suppression, but for other applications of HFCs as well. For example, new HFC refrigerants (and blends) are likely to be slightly flammable [29,30]. Hence, understanding their flammability in the presence of hydrocarbons (and any anomalous behavior) is important for their fire-safe use in buildings.

\section{ACKNOWLEDGEMENTS}

The work was supported by the Boeing Company. The authors thank Wing Tsang and Don Burgess, of NIST, and John Reinhardt at the FAA Technical Center for helpful conversations, as well as Med Colket and Ken Smith of UTRC for providing thermodynamic data for 2-BTP which was essential to this work.

\section{REFERENCES}

[1] Reinhardt, J.W., "Behavior of Bromotrifluoropropene and Pentafluoroethane When Subjected to a Simulated Aerosol Can Explosion," Federal Aviation Administration DOT/FAA/AR-TN04/4, Washington, D.C., 2004, 20 p.

[2] Reinhardt, J.W., "Minimum Performance Standard for Aircraft Cargo Compartment Halon Replacement Fire Suppression Systems (2nd Update)," Federal Aviation Administration DOT/FAA/AR-TN05/20, Washington, D.C., 2005, 30 p.

[3] Reinhardt, J.W., "Prevention of a Simulated Aerosol Can Explosion With a Mixture of Halon 1301 and Nitrogen," Federal Aviation Administration DOT/FAA/AR-TN08/49, Washington, D.C., 2008, 16 p. 
[4] Gmurczyk, G.W., Grosshandler, W.L. and Lowe, D.L., 1994. Suppression Effectiveness Of Extinguishing Agents Under Highly Dynamic Conditions. Fire Safety Science 4: 925-936. http://dx.doi.org/10.3801/IAFSS.FSS.4-925

[5] Gmurczyk, G. and Grosshandler, W., (1994) Suppression of High-Speed C2H4/Air Flames With C1-Halocarbons, Proceedings of the Combustion Institute 25: 1497-1503, http://dx.doi.org/10.1016/S0082-0784(06)80794-0

[6] Gmurczyk, G.W. and Grosshandler, W.L., "Suppression of High Speed Flames and Quasidetonations," Evaluation of Alternative In-Flight Fire Suppressants for Full-Scale Testing in Simulated Aircraft Engine Nacelles and Dry Bays, Grosshandler W., Gann R G, and Pitts W M (eds.), National Institute of Standards and Technology Gaithersburg, MD, 1995, p. 9.

[7] Hamins, A., Gmurczyk, G., Grosshandler, W.L., Presser, C., and Seshadri, K., "Flame Suppression Effectiveness," Evaluation of Alternative In-Flight Fire Suppressants for Full-Scale Testing in Simulated Aircraft Engine Nacelles and Dry Bays, Grosshandler W.L., Gann R G, and Pitts W M (eds.), National Institute of Standards and Technology Gaithersburg, MD, 1994, p. 345.

[8] Shebeko, Y.N., Azatyan, V.V., Bolodian, I.A., Navzenya, V.Y., Kopyov, S.N., Shebeko, D.Y., and Zamishevski, E.D., (2000) The Influence of Fluorinated Hydrocarbons on the Combustion of Gaseous Mixtures in a Closed Vessel, Combustion and Flame, 121:542-547, http://dx.doi.org/10.1016/S0010-2180(99)00168-6

[9] Suzuki, A., Inomata, T., Jinno, H., and Moriwaki, T., (1991) Effect of Bromotrifluoromethane on the Ignition in Methane and Ethane-Oxygen-Argon Mixtures Behind Shock-Waves, Bulletin of the Chemical Society of Japan, 64: 3345-3354, http://dx.doi.org/10.1246/bcsj.64.3345

[10] Takahashi, K., Inomata, T., Moriwaki, T., and Okazaki, S., (1989) The Addition Effect of CH3I on the Ignition of CH4, Bulletin of the Chemical Society of Japan, 62: 636-638, http://dx.doi.org/10.1246/bcsj.62.636

[11] Takahashi, K., Inomata, T., Moriwaki, T., and Okazaki, S., (1988) The Addition Effect of CH3Br and $\mathrm{CH} 3 \mathrm{Cl}$ on Ignition of $\mathrm{CH} 4$ by Shock-Wave, Bulletin of the Chemical Society of Japan, 61: 3307-3313, http://dx.doi.org/10.1246/bcsj.61.3307

[12] Takahashi, K., Inomata, T., Moriwaki, T., and Okazaki, S., (1989) The Addition Effects of Methyl Halides on Ethane Ignition Behind Reflected Shock-Waves, Bulletin of the Chemical Society of Japan, 62: 2138-2145, http://dx.doi.org/10.1246/bcsj.62.2138

[13] Ikeda, E. and Mackie, J.C., (2001) An Experimental and Modelling Study of Ignition Delays in Shock-Heated Ethane-Oxygen-Argon Mixtures Inhibited by 2H-Heptafluoropropane, Zeitschrift fur Physikalische Chemie-International Journal of Research in Physical Chemistry \& Chemical Physics, 215: 997-1009, http://dx.doi.org/10.1524/zpch.2001.215.8.997

[14] Mawhinney, J.R., Dlugogorski, B.Z. and Kim, A.K., 1994. A Closer Look at the Fire Extinguishing Properties of Water Mist. Fire Safety Science 4: 47-60. http://dx.doi.org/10.3801/IAFSS.FSS.4-47

[15] Hamins, A., McGrattan, K., and Forney, G.P., "Unwanted Accelerated Burning After Suppressant Delivery," National Institute of Standards and Tech. SP-1004, Gaithersburg, MD, 2003, 48 p.

[16] Holmstedt, G., Andersson, P. and Andersson, J., 1994. Investigation of Scale Effects on Halon and Halon Alternatives Regarding Flame Extinguishing, Inerting Concentration and Thermal Decomposition Products. Fire Safety Science 4: 853-864. http://dx.doi.org/10.3801/IAFSS.FSS.4$\underline{853}$

[17] Katta, V.R., Takahashi, F., and Linteris, G.T., (2006) Fire-Suppression Characteristics of $\mathrm{CF}_{3} \mathrm{H}$ in a Cup Burner, Combustion and Flame, 144: 645-661, http://dx.doi.org/10.1016/j.combustflame.2005.09.006

[18] Linteris, G.T. and Truett, L., (1996) Inhibition of Premixed Methane-Air Flames by Fluoromethanes, Combustion and Flame, 105: 15-27, http://dx.doi.org/10.1016/0010$\underline{2180(95) 00152-2}$ 
[19] Linteris, G.T., Burgess, D.R., Babushok, V., Zachariah, M., Tsang, W., and Westmoreland, P., (1998) Inhibition of Premixed Methane-Air Flames by Fluoroethanes and Fluoropropanes, Combustion and Flame, 113: 164-180, http://dx.doi.org/10.1016/S0010-2180(97)00216-2

[20] Linteris, G.T., "Acid Gas-Production in Inhibited Flames," Halon Replacements: Technology and Science, Miziolek A. and Tsang W (eds.), American Chemical Society Washington, DC, 1994, p. 225, http://dx.doi.org/10.1021/bk-1995-0611.ch019

[21] Linteris, G.T., "Effect of inhibitor concentration on the inhibition mechanism of fluoromethanes in premixed methane-air flames," Halon Replacements, Miziolek A.W. and Tsang W (eds.), ACS Symposium Series 611, American Chemical Society Washington, D.C., 1995, p. 260, http://dx.doi.org/10.1021/bk-1995-0611.ch021

[22] Takizawa, K., Takahashi, A., Tokuhashi, K., Kondo, S., and Sekiya, A., (2005) Burning Velocity Measurement of Fluorinated Compounds by the Spherical-Vessel Method, Combustion and Flame, 141: 298-307, http://dx.doi.org/10.1016/j.combustflame.2005.01.009

[23] Linteris, G.T. and Gmurczyk, G.W., "Prediction of HF formation during suppression," Fire Suppression System Performance of Alternative Agents in Aircraft Engine and Dry Bay Laboratory Simulations, R.G.Gann (ed.), National Institute of Standards and Technology Gaithersburg, MD, 1995, p. 201.

[24] Glassman, I., Combustion, Academic Press, San Diego, CA, 1996, p. 15.

[25] Turns, S.R., An Introduction to Combustion, McGraw-Hill, Boston, 2000, p. 32.

[26] The Element Potential Method for Chemical Equilibrium Analysis: Implementation in the Interactive Program STANJAN," Stanford University ME 270 HO no 7, Stanford, CA, 1986.

[27] Gordon, S. and McBride, B.J., "Computer Program for Calculation of Complex Chemical Equilibrium Compositions and Applications," NASA Glenn Research Center NASA Reference Publication 1311, Cleveland, OH, 1996.

[28] Westmoreland, P.R., Burgess, D.R.F.Jr., Zachariah, M.R., and Tsang, W., (1994) Fluoromethane Chemistry and Its Role in Flame Suppression, Proceedings of the Combustion Institute, 25: 15051511, http://dx.doi.org/10.1016/S0082-0784(06)80795-2

[29] Linteris, G.T., (2006) Burning Velocity of 1,1 Difluoroethane (R-152a), ASHRAE Transactions, 112: 448-458,

[30] Kondo, S., Takizawa, K., Takahashi, A., Tokuhashi, K., and Sekiya, A., (2009) Flammability Limits of Five Selected Compounds Each Mixed with HFC-125, Fire Safety Journal, 44: 192-197, http://dx.doi.org/10.1016/j.firesaf.2008.06.001 